\title{
Evaluation of air samplers and filter materials for collection and recovery of airborne norovirus
}

Uhrbrand, Katrine; Kalevi Koponen, Ismo; Schultz, Anna Charlotte; Madsen, Anne Mette

Published in:

Journal of Applied Microbiology

Link to article, DOI:

10.1111/jam. 13588

Publication date:

2018

Document Version

Peer reviewed version

Link back to DTU Orbit

Citation $(A P A)$ :

Uhrbrand, K., Kalevi Koponen, I., Schultz, A. C., \& Madsen, A. M. (2018). Evaluation of air samplers and filter materials for collection and recovery of airborne norovirus. Journal of Applied Microbiology, 124(4), 990-1000. https://doi.org/10.1111/jam.13588

\section{General rights}

Copyright and moral rights for the publications made accessible in the public portal are retained by the authors and/or other copyright owners and it is a condition of accessing publications that users recognise and abide by the legal requirements associated with these rights.

- Users may download and print one copy of any publication from the public portal for the purpose of private study or research.

- You may not further distribute the material or use it for any profit-making activity or commercial gain

- You may freely distribute the URL identifying the publication in the public portal 
Article type : Special Issue article

Evaluation of air samplers and filter materials for collection and recovery of airborne norovirus

Katrine Uhrbrand ${ }^{1,2^{*}}$, Ismo K. Koponen ${ }^{1}$, Anna Charlotte Schultz ${ }^{2}$ and Anne Mette Madsen ${ }^{1}$

${ }^{1}$ National Research Centre for the Working Environment, Copenhagen $\varnothing$, Denmark

${ }^{2}$ Division of Microbiology and Production, National Food Institute, Technical University of Denmark, Kgs. Lyngby, Denmark

*Corresponding author. E-mail address: kau@nrcwe.dk

Running title: Evaluation of air sampling methods for norovirus

\section{Abstract:}

Aims: The aim of this study was to identify the most efficient sampling method for quantitative PCRbased detection of airborne human norovirus (NoV).

Methods and Results: A comparative experiment was conducted in an aerosol chamber using aerosolised murine norovirus (MNV) as a surrogate for NoV. Sampling was performed using a nylon (NY) filter in conjunction with four kinds of personal samplers; Gesamtstaubprobenahme sampler This article has been accepted for publication and undergone full peer review but has not been through the copyediting, typesetting, pagination and proofreading process, which may lead to differences between this version and the Version of Record. Please cite this article as doi: $10.1111 /$ jam. 13588

This article is protected by copyright. All rights reserved. 
(GSP), Triplex-cyclone sampler (TC), 3-piece closed-faced Millipore cassette (3P) and a 2-stage NIOSH cyclone sampler (NIO). In addition, sampling was performed using the GSP sampler with four different filter types; NY, polycarbonate (PC), polytetrafluoroethylene (PTFE) and gelatine (GEL). The sampling efficiency of MNV was significantly influenced by both sampler and filter type. The GSP sampler was found to give significantly $(P<0.05)$ higher recovery of aerosolised MNV than 3P and NIO. A higher recovery was also found for GSP compared with TC, albeit not significantly. Finally, recovery of aerosolised MNV was significantly $(P<0.05)$ higher using NY than PC, PTFE and GEL filters. Conclusions: The GSP sampler combined with a nylon filter was found to be the best method for personal filter-based sampling of airborne NoV.

Significance and Impact of the Study: The identification of a suitable NoV air sampler is an important step towards studying the association between exposure to airborne NoV and infection.

Keywords: air sampling; norovirus; bioaerosol; aerosolisation; GSP sampler; filters; airborne exposure

\section{Introduction:}

Human norovirus (NoV) is the main etiological agent responsible for gastrointestinal illness in all age groups (Patel et al. 2009). Transmission of NoV occurs via the faecal-oral route either directly by person-to-person contact or indirectly through contaminated food, water or fomites (D'Souza et al. 2006; Koopmans et al. 2004; Marks et al. 2003). In addition, dissemination of NoV through aerosol droplets, especially following vomiting, has been inferred to occur based on epidemiological information from NoV outbreaks (Marks et al. 2000; Marks et al. 2003). Such airborne transmission of NoV is believed to occur via inhalation and subsequent ingestion (Marks et al. 2000). However, at this point the importance of airborne transmission is not well defined and only few studies relating to detection of airborne NoV exist (Bonifait et al. 2015; Brooks et al. 2005; Masclaux et al. 2014; Uhrbrand et al. 2011; Uhrbrand et al. 2017).

This article is protected by copyright. All rights reserved. 
To contribute with a new understanding of the extent of airborne transmission of NoV and other enteric viruses such as human adenovirus (AdV), it is essential to have sensitive and robust methods for sampling of viruses from air. Collection of aerosolised viruses is normally conducted by creating a vacuum through a sampling apparatus. This will result in air entering the devices where aerosolised viruses will be retained by physical separation (Gilbert et al. 2009). Different principles such as impaction, impingement and filtration have been used for viral aerosol sampling (Verreault et al. 2008).

Despite recent advancements in the development of a cultivation system for NoV (Ettayebi et al. 2016; Jones et al. 2015), it is not yet possible to propagate NoV on a routine basis and detection still relies on molecular methods such as RT-PCR. Therefore, it is important that the air sampling method chosen for collection of NoV is compatible with the RT-PCR detection format. Furthermore, for studying the association between exposure and infection, the use of a personal sampler that simulates individual exposure by allowing sampling of air from the breathing zone over a longer time period, e.g. an entire day, would be preferable. While solid impactors using e.g. agar medium have previously been used for sampling and detection of airborne enteric viruses in hospital settings and solid waste facilities, NoVs have not been successfully detected in air using this sampling strategy (Carducci et al. 2000; Carducci et al. 2011; Carducci et al. 2013), and it may thus not be the best approach for sampling of NoV. In addition, impactors may be better suited for shortterm sampling purposes due to issues with dehydration (Bosch et al. 2011). The use of impingers with a liquid collection medium prevents desiccation and facilitates the extraction of genetic material for subsequent analysis (Verreault et al. 2008) but often requires concentration of the collection medium by e.g. ultrafiltration prior to viral detection. Impingers have previously been used for detection of NoV genomes present in air collected downwind from a biosolid land application site (Brooks et al. 2005) and in healthcare facilities during a NoV outbreak (Bonifait et al. 2015). Nevertheless, impingers may be less practical for personal sampling of airborne NoV because of restrictions in movements of the person wearing the liquid containing sampler and issues with 
evaporation of the medium during sampling for more than one hour. In addition, impingers have been reported to be inefficient for sampling of sub-micrometer and ultrafine virus particles, with collection efficiencies below $10 \%$ for viruses in the size range of 30-100 nm (Hogan et al. 2005). Since most impactors and impingers cannot efficiently retain particles with an aerodynamic size below 500 $\mathrm{nm}$, filters have often been used for sampling of airborne viruses instead (Verreault et al. 2008). Filter-based sampling is both compatible with personal sampling over a longer period and quantitative molecular detection, and therefore appears to be a promising strategy for collection of airborne NoV. Filter-based sampling methods have indeed been used successfully for both personal and stationary sampling of NoV as well as other enteric viruses (Masclaux et al. 2014; Tseng et al. 2010; Uhrbrand et al. 2011; Uhrbrand et al. 2017; Wallis et al. 1985). However, more data regarding which type of filter-based sampler and filter material that result in the best collection and recovery of NoV is warranted.

The aim of this study was to identify the most efficient method for personal filterbased sampling of airborne NoV. To investigate this we conducted: a) a comparative filter spiking experiment with NoV, AdV, and murine norovirus (MNV), and b) a comparative sampling experiment in an aerosol chamber using aerosolised MNV as a surrogate for NoV.

\section{Materials and methods}

\section{Viruses}

MNV strain 1 (kindly provided by Dr Virgin, Washington University School of Medicine, USA) was used in both filter spiking and virus aerosolisation experiments. In addition, stool samples of NoV GII.4 variant 2006b and AdV serotype 41 (kindly provided by Dr Kjell-Olof Hedlund, Swedish Institute for Infectious Disease Control, Sweden) were used for filter spiking experiments. The AdV strain was included to also obtain knowledge on the recovery of an enteric DNA virus from the

This article is protected by copyright. All rights reserved. 
filters. Mengovirus, MC $_{0}$, (ATTC VR-2310, kindly provided by Prof Albert Bosch, University of Barcelona, Spain) was used as a process control in both filter spiking and virus aerosolisation experiments.

MNV was propagated in RAW264.7 cells (ATCC TIB-71) (Wobus et al. 2004) and titrated by plaque assay (Cannon et al. 2006) to $2.67 \times 10^{7} \mathrm{PFU} / \mathrm{ml}$ and by endpoint RT-PCR to $2 \times 10^{8}$ RT-PCR U/ml. MC 0 was propagated in HeLA cells (ATCC CCL-2) (Martin et al. 1996) and titrated by $\mathrm{TCID}_{50}$ assay (Reed et al. 1938 ) to $1 \times 10^{8} \mathrm{TCID}_{50} / \mathrm{ml}$ and by endpoint RT-PCR to $1 \times 10^{9} \mathrm{RT}-\mathrm{PCR} \mathrm{U} / \mathrm{ml}$.

The NoV GII.4 and AdV-positive stool samples were quantified by endpoint real-time RT-PCR to contain $1 \times 10^{9} \mathrm{RT}-\mathrm{PCR} \mathrm{U} / \mathrm{ml}$ and $1 \times 10^{10} \mathrm{PCR}$ detectable $\mathrm{U}(\mathrm{PDU}) / \mathrm{ml}$, respectively.

\section{Filter spiking experiment}

Spiking experiments were performed on four $37 \mathrm{~mm}$ filters; MAGNA nylon membrane

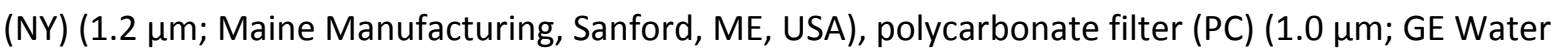
\& Process Technology, Trevose, PA, USA), Fluoropore membrane filter (PTFE) (1 $\mu \mathrm{m}$; Millipore,

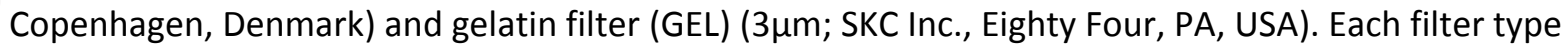
was spiked in duplicates on two separate occasions with $10 \mu \mathrm{l}$ of 10 -fold serial dilutions of viruses in final quantities of $2.0 \times 10^{1}-2.0 \times 10^{4}$ genomic copies (GC) of NoV GII, $2.0 \times 10^{1}-2.0 \times 10^{4}$ RT-PCR U of MNV and $4.0 \times 10^{1}-4.0 \times 10^{4}$ PDU of AdV. A non-spiked filter was used as a negative process control in each experiment.

\section{Virus aerosolisation experiment}

Virus aerosolisation was performed in a customised aerosol chamber with a volume of $0.66 \mathrm{~m}^{3}$ made of stainless steel (Nørgaard et al. 2009). A schematic figure of the experimental design is presented in Figure 1. A flow bubble generator (Ulevicius et al. 1997) was used to generate aerosol from a 250

This article is protected by copyright. All rights reserved. 
$\mathrm{ml} \mathrm{MNV} \mathrm{solution} \mathrm{containing} \mathrm{approximately} 10^{6} \mathrm{RT}-\mathrm{PCR} \mathrm{U} / \mathrm{ml}$ (corresponding to $\sim 10^{5} \mathrm{PFU} / \mathrm{ml}$ ) suspended in sterile MilliQ-water. The aerosolised suspension passed through an electrostatic charge neutraliser (aerosol neutraliser 3054A, TSI Inc., Shoreview, MN, USA) before entering the chamber. The air flow from the bubble generator into the chamber was $22 \mathrm{lpm}$ and the total flow out from the chamber was $38.8 \mathrm{Ipm}$. The generated aerosols were diluted with supplementary air entering the chamber through a HEPA filter with a flow of $16.8 \mathrm{lpm}$. A conditioning period of $30 \mathrm{~min}$ was used after turning the bubble generator on to ensure that a steady state in the concentration of MNV aerosols was reached in the chamber before air sampling. Particle concentration and size distribution inside the chamber was monitored during aerosolisation and sampling using electric low pressure impactor (ELPI+) (Dekati Ltd., Kangasala, Finland). Measurements were done with one second resolution and 15 bins in the size range $6 \mathrm{~nm}$ to $10 \mu \mathrm{m}$. The ELPI+ used greased aluminum discs for size distributed collection of the aerosolized particles. Before and after each experiment, the chamber was flushed with filtered laboratory air and the particle background level in the chamber measured using the ELPI+.

Sampling of MNV aerosols were performed side-by-side in duplicates using: a) NY, PC, PTFE and GEL filters each in conjunction with a inhalable Gesamtstaubprobenahme sampler (GSP; BIG Inc., Waltham, MA, USA) and b) GSP samplers, Triplex-cyclone samplers (TC), 3-piece closed-face cassettes (3P; Millipore, Copenhagen, Denmark) and 2-stage NIOSH bioaerosol cyclone BC251 samplers (NIO; Kindly provided by Dr William G. Lindsley, Center of Disease Control, GA, USA) each mounted with a NY filter. The latter sampler (NIO) collected and size-fractionated the viral aerosols into three fractions: stage 1 ( $15 \mathrm{ml}$ tube) collecting particles $>4 \mu \mathrm{m}$; stage $2(1.5 \mathrm{ml}$ tube) collecting particles between 1-4 $\mu \mathrm{m}$ and the filter stage collecting particles $<1 \mu \mathrm{m}$. Samplers

The comparative filter sampling experiment setup was performed on four separate occasions (A-D), while the comparison of the sampler type was conducted on two separate occasions (C-D). Hence, both a filter sampling and a sampler comparison setup were performed on 
occasion C and D. Between the filter sampling and sampler setup the aerosol generator was switched off and the chamber flushed with filtered laboratory air until the particle concentration returned to the background level, as measured with the ELPI+. After each experiment, disinfection of the chamber was conducted using UV-light and $1 \%$ Virkon ${ }^{\circledR}$ (Kebo Med, Glostrup, Denmark) followed by thorough rinsing with sterile MilliQ-water to remove any residual disinfectant. As a negative process control, a 30 min sampling was conducted in the chamber prior to each aerosolisation experiment using GPS with a NY filter. All experiments were conducted at ambient laboratory temperature and humidity.

After sampling, filters from the samplers and the ELPI+ aluminium discs were transferred to a $47 \mathrm{~mm}$ petri dish with sterile forceps and stored a $4^{\circ} \mathrm{C}$ until virus elution and RNA extraction could be carried out.

\section{Extraction and quantification of viruses}

Viruses were eluted and extracted directly from the filters as previously described (Uhrbrand et al. 2011). Briefly, filters were incubated for $15 \mathrm{~min}$ in $3 \mathrm{ml}$ of NucliSENS lysis buffer (BioMerieux, Herlev, Denmark). Lysis buffer was also added to the $1.5 \mathrm{ml}$ and $15 \mathrm{ml}$ tubes used for collection of viruses in stage 1 and 2 of the NIO sampler followed by vortexing and incubation. Total nucleic acid purification was performed on the entire lysate using NucliSENS miniMAG system (BioMerieux, Herlev, Denmark) according to the manufacturer's instructions. Nucleic acids were eluted in $100 \mu \mathrm{l}$ of NucliSENS elution buffer. To quality assure the extraction performance and control for false-negative samples, mengovirus $\left(\mathrm{MC}_{0}\right)$ was spiked on the air filters in a concentration of $10^{5}$ RT-PCR $U$ and used as an extraction control.

Detection of viruses was performed in duplicate on a 96-well plate format of ABI Step One (Applied Biosystems, Nærum, Denmark). 
NoV GII, MNV and $\mathrm{MC}_{0}$ RNA were detected by reverse transcriptase real-time polymerase reaction (qRT-PCR) using the RNA UltraSense one-step quantitative RT-PCR system (Invitrogen, Taastrup, Denmark) and previously described primers and probes for NoV GII (Kageyama et al. 2003; Loisy et al. 2005), MNV (Rawsthorne et al. 2009) and $\mathrm{MC}_{0}$ (Costafreda et al. 2006). The qRT-PCR was carried out in a total of $25 \mu$ reaction mixture constituting $5 \mu$ l of extracted viral RNA and $20 \mu \mathrm{l}$ of qRT-PCR reaction mixture containing $1 \times$ UltraSense reaction mix, $500 \mathrm{nM}$ forward primer, $900 \mathrm{nM}$ reverse primer, $250 \mathrm{nM}$ Probe, $1 \times$ Rox reference dye and $1 \times$ UltraSense enzyme mix. Reactions conditions were as previously described (Le Guyader et al. 2009).

AdV DNA was detected by qPCR as previously described using a QuantiTech Probe PCR kit (QIAGEN, Copenhagen, Denmark) with primers JTVXF/JTVXR and probe JTVXP (Jothikumar et al. 2005).

Quantification was performed using standard curves generated from 10-fold dilutions series of NoV GII.4 RNA transcripts (Gentry et al. 2009), extracted RNA of MNV and $M_{0}$ or DNA of AdV.

\section{Data analysis}

In the filter spiking experiment, virus recovery was calculated from the number of viral genomes (RT-PCR U or PDU) detected on the filter as a percentage to the number of viral genomes (RT-PCR U or PDU) spiked on the filters. The virus recoveries from the two highest spiking levels (high and medium concentration) were used for statistical analysis as these were within the quantitative range of the detection method. Prior to statistical analysis the recovery data obtained from the medium spiking concentration of MNV were log transformed to approximate normal distribution, while the recovery data from all other virus types and spiking levels were already normally distributed. Proc mixed models were used to evaluate the relationship between recovery 
and filter type as dependable variable, while concentration and occasion were included as random variables. Moreover, the recoveries of MNV, NoV GII and AdV as affected by filter type were studied for each spiking level using General Linear Models (GLM)."

In the aerosolisation experiments, the number of MNV genomes recovered with the various filter and sampler types were normalised according to the total number of particles in the aerosol chamber during sampling measured using ELPI+. This was done to minimise differences between sampling occasions due to variation in the concentration of MNV aerosols present in the chamber. The extraction efficiencies from the air samples were calculated from the number of $\mathrm{MC}_{0}$ detected as a percentage to the number of $\mathrm{MC}_{0}$ spiked on the filters. Both normalised MNV recovery and $\mathrm{MC}_{0}$ extraction efficiency data were normally distributed. Proc mixed models were used to evaluate the relationship between the recoveries with filter or sampler type as dependable variables and occasion as random variables. GLM were used to study both the normalised recovery of MNV and extraction efficiency $\mathrm{MC}_{0}$ as affected by filter and sampler type. For the NIO sampler, the recovery of MNV was calculated based on the total sum of MNV collected from the difference stages.

For the aerosol chamber experiments averaged size distribution spectrums were fitted using log-normal distribution in order to obtain the geometric mean aerodynamic diameter (GMD) of the measured aerosol size distribution of total particles and MNV (Makela et al. 2000). All statistical analysis were carried out in SAS statistical software version 9.4 (SAS Institute, Cary, NC, USA) and results with $P$ values $<0.05$ were in all analysis considered statistically significant.

This article is protected by copyright. All rights reserved. 


\section{Results}

\section{Filter spiking experiment}

The recovery efficiencies in percentage for MNV, NoV GII and AdV spiked onto PC, PTFE, NY and GEL filters and ELPI ${ }^{+}$aluminium discs are presented in Table 1. The spiking concentrations were found to have a significant effect on the recoveries of NoV GII ( $P=0.0003)$ and $\operatorname{AdV}(P<0.0001)$ from the filters, and a significant effect $(P<0.0001)$ of the filter type was found for all viruses. Compared with all other filter types, the GEL filter was found to give a significantly lower recovery of MNV and NoV GII in both medium and high spiking concentrations as well as for AdV at high spiking concentration. At medium spiking concentrations of AdV, significantly lower recovery was also found from the GEL filter compared with PC and NY, but no significant difference was found between GEL, PTFE and ELPI+. No significant differences in the recovery of MNV and NoV GII were found at medium spiking concentrations when comparing PTFE, PC, NY and ELPI+, while PC was found to give significantly higher MNV recovery than PTFE and NY at high spiking concentrations but significantly lower recovery of NoV GII than PTFE at high spiking concentrations (Table 1).

\section{Virus aerosolisation experiment}

The recovery of aerosolised MNV using various filter-based samplers and filter materials are shown in Figure 2. Despite normalising the MNV concentration according to the total particle concentration in the aerosol chamber during the air sampling, a significant difference in recovery of aerosolised MNV was found between sampling occasions in the experiments comparing filter materials $(P<0.0001)$. No significant difference in recovery of aerosolised MNV was found between sampling occasions $(P=0.2377)$ in the experiments comparing sampler types.

This article is protected by copyright. All rights reserved. 
The type of filter material used for air sampling was found to have a significant effect on the recovery of aerosolised MNV $(P<0.0001)$. Recovery of aerosolised MNV was found to be significantly higher for NY than for PC, PTFE and GEL filters. In addition, PC resulted in significantly higher recovery of aerosolised MNV than PTFE and GEL, while GEL resulted in significantly lower recovery than all of the other filter materials (Figure $2 \mathrm{~A}$ ). Using $\mathrm{MC}_{0}$ as extraction control, the efficiencies to extract viruses collected onto the filters were calculated to be $62 \pm 26 \%, 86 \pm 18 \%$, $62 \pm 13 \%$ and $21 \pm 3 \%$ from NY, PC, PTFE and GEL, respectively. The recovery of the $\mathrm{MC}_{0}$ extraction control from filters was found to be significantly affected by both filter type $(P<0.0001)$ and occasion $(P=0.0002)$. $\mathrm{MC}_{0}$ recovery was significantly higher from PC than from PTFE, NY and GEL, while GEL resulted in significantly lower recovery compared with all other filter types.

The sampler type was found to have a significant effect $(P=0.0127)$ on the recovery of aerosolised MNV. The GSP sampler was found to give significantly higher recovery of aerosolised MNV than both 3P and NIO. A higher recovery was also observed for GSP compared with TC, albeit not significantly (Figure $2 \mathrm{~A}$ ). Based on the $\mathrm{MC}_{0}$ extraction control, the viral extraction efficiencies from the filters were calculated to be $79 \pm 19 \%, 62 \pm 185 \%, 72 \pm 19 \%$ and $61 \pm 14 \%$ from the GSP, $3 P$, TC and NIO samples, respectively. Both sampler type $(P<0.0001)$ and occasion $(P<0.0001)$ were found to significantly affect the recovery of the $\mathrm{MC}_{0}$ extraction control, with GSP and TC resulting in a significantly higher recovery of $\mathrm{MC}_{0}$ than $3 \mathrm{P}$ and NIO. With the NIO sampler, $91.4 \pm 3.3 \%$ of the recovered MNV was found on the filter in the $<1 \mu \mathrm{m}$ aerodynamic size fraction, $5.5 \pm 2.7 \%$ were found to be between $1-4 \mu \mathrm{m}$, and $3.1 \pm 1.5 \%$ were $>4 \mu \mathrm{m}$.

The total particle concentration in the chamber during the aerosolisation of MNV was measured to be $2.6 \times 10^{10}, 2.5 \times 10^{10}, 2.0 \times 10^{10}$, and $1.7 \times 10^{10}$ particles $/ \mathrm{m}^{3}$ air on occasion $A, B, C$ and $D$, respectively, while the mean particle background level was determined to be $2.1 \times 10^{9} \pm 3.6 \times 10^{8}$ particles $/ \mathrm{m}^{3}$. Based on the total number of MNV quantified on the $14 \mathrm{ELPI}+$ aluminum size discs, the MNV concentration in the chamber during the aerosolisation experiments were estimated to be

This article is protected by copyright. All rights reserved. 
$4.5 \times 10^{3}, 3.8 \times 10^{3}, 4.7 \times 10^{3}$ and $3.9 \times 10^{3} \mathrm{RT}-\mathrm{PCR} \mathrm{U} / \mathrm{m}^{3}$ air on occasion $\mathrm{A}, \mathrm{B}, \mathrm{C}$, and $\mathrm{D}$, respectively. The size distribution of total particles and aerosolised MNV in the chamber during sampling determined using ELPI+ is depicted in Figure 3 along with the size distribution of the background particle level. GMD of total aerosol particles and MNV was $33.0 \pm 2.3$ and $126.8 \pm 2.9 \mathrm{~nm}$, respectively. Using $\mathrm{MC}_{0}$, the viral extraction recovery from the EPLI+ aluminum discs was determined to be $76 \pm 21 \%$.

\section{Discussion}

To gain a better understanding of the significance of exposure to NoV aerosols and its association with infection it is imperative to have efficient air sampling methods for NoV. The present study provides new information regarding the suitability of different personal filter-based air samplings methods to recover aerosolised MNV as a surrogate for NoV. Although several studies comparing different air samplers and filter materials have previously been conducted using e.g. aerosolised bacteriophages such as MS2 as models for collection and recovery of human pathogenic viruses (Burton et al. 2007; Gendron et al. 2010; Tseng et al. 2005), this is to our knowledge the first comparative study to use aerosolised MNV. MNV is closely related and shares many biological and molecular properties with NoV. With a size of 28-35 nm in diameter, icosahedral shape and a buoyant density of $1.36 \pm 0.04 \mathrm{~g} / \mathrm{cm}^{2} \mathrm{MNV}$ has similar characteristic as NoV (Wobus et al. 2004) making MNV a promising model for evaluating the adeptness of air sampling methods for NoV. In our study, the feasibility of using MNV as a surrogate for NoV was demonstrated in the filter spiking experiment as similar trends in the recovery of MNV and NoV GII was found for the different filter types. Hence, at least when it comes to elution and extraction of the viruses from the filters MNV seems to be a suitable model for NoV. Moreover, since AdV was also successfully recovered from the spiked filters it shows that the processing method employed is efficient in recovering both RNA and DNA viruses from the air sampling filters. This indicates that the method can also be used for recovery of a wide panel of other airborne enteric viruses, in addition to NoV. The demonstrated

This article is protected by copyright. All rights reserved. 
ability of the method to recover AdV from the air sampling filters is of particular value in relation to air sampling from occupational settings such as wastewater treatment plants. AdVs are used as viral indicators of water quality due to their stability and presence in high concentrations in untreated wastewater all year round (Rames et al. 2016). For a similar reason, AdVs also have recently been suggested as potential indicator organisms for occupational exposure to air contaminated with fecal matter (Carducci et al. 2016) . Moreover, AdVs could potentially be used for development of quantitative microbial risk assessment (QMRA) models to assess the risk associated with inhalation of bioaerosols as recently demonstrated by Carducci et al. (2016). The successful future use of QMRA is, however, reliant on collection of quantitative data on e.g. the exposure to airborne AdV, the correlation between AdV and other airborne enteric viruses, and dose-response relationships.

The filter material employed for sampling of aerosolised MNV was found to have a significant effect on MNV recoveries with NY>PC>PTFE $>$ GEL. The superiority of the NY filter to recover aerosolised MNV found in our study can be attributed to a higher physical collection efficiency, higher extraction efficiency from the filter or a combination hereof. To our knowledge, no other studies have previous compared the collection efficiency and/or recovery efficiency of the NY filter in regards to sampling of airborne enteric viruses. However, as the PC filters resulted in significantly higher recovery of both the $\mathrm{MC}_{0}$ extraction control and high spiking concentrations $\mathrm{MNV}$ and AdV than NY, indications are that NY's superiority is due to greater physical collection of MNV, at least in comparison with PC. The physical collection efficiency of MS2 aerosols has previously been reported to be lower $(68 \%)$ for PC filters (pore size $1 \mu \mathrm{m}$ ) than that $(>96 \%)$ of both PTFE (pore size $1 \mu \mathrm{m}$ ) and GEL (pore size3 $\mu \mathrm{m}$ ) (Burton et al. 2007). The reported differences in collection efficiencies between filter types are presumably because of better internal capture capacity of PTFE and GEL due to their complex three-dimensional web like structure, compared with the PC filter that consists of a thin and smooth film with circular pores (Burton et al. 2007). With a multi-layered structure bearing resemblance to that of PTFE and GEL, the internal viral capture capacity of NY is most likely closer to that of PTFE and GEL than of PC.

This article is protected by copyright. All rights reserved. 
Despite the higher MS2 collection efficiencies previously reported for PTFE and GEL

(Burton et al. 2007), the recovery of aerosolised MNV from these filters were found to be significantly lower than that of PC. These findings are similar to that of Gendron et al. (2010) who also found a higher recovery of aerosolised MS2 genomes from PC compared with PTFE, albeit not significantly. The discrepancies observed between the filters' capacity to capture virus versus the ability to recover the viruses from the filters, clearly demonstrate the importance of having a successful elution of the viruses from the filter to achieve a high virus recovery from an air sample. Thus, when evaluating different filter-based air sampling methods, it is important not only to look at the physical collection of the viruses, but also at the subsequent viral elution, extraction and detection steps. The exposure-level required to cause NoV infection upon inhalation is unknown, but with an estimated oral ID $\mathrm{D}_{50}$ of disaggregated NoV as low as 18 particles in secretor-positive individuals (Teunis et al. 2008), it seems essential to avoid viral loss during processing of the air samples. In the present study, a direct elution from the filter with lysis buffer followed by nucleic acid extraction of the entire sample volume was used to recovery viruses from the air filters. By using this approach, we avoid unnecessary processing steps for viral elution and concentration prior to nucleic acid extraction that could otherwise lead to loss of viruses.

The study demonstrated an overall poor performance of the GEL filter both in regards to recovery of aerosolised MNV and spiked MNV, NoV GII and AdV as well as of the $\mathrm{MC}_{0}$ extraction control. As the GEL filter was completely dissolved in the lysis buffer and the entire volume used for nucleic acid extraction, the poor recovery is likely a result of co-extraction of gelatine components causing inhibition of the PCR-detection rather than problems with inadequate viral elution or loss during processing. While GEL filters may be useful for sampling and cultivation-based detection of infectious viruses as reported in some studies (Neve et al. 2003; Zuo et al. 2013), they do not appear to be compatible with PCR-based detection. Furthermore, their use is limited since sampling in environments with low and high humidity and temperature can cause the gelatine to dry out and break or dissolve (Verreault et al. 2008). Finally, as GEL filters are prone to dry out during long-term 
sampling (Burton et al. 2007), a maximum sampling time of $30 \mathrm{~min}$ is recommended by the manufacture, making GEL a poor choice for e.g. sampling of NoV during a whole working day.

The sampler type employed was found to have a significant effect on the recovery of aerosolised MNV. The GSP followed by TC gave the highest recovery of aeorosolised MNV. However, as significantly higher recovery of the $\mathrm{MC}_{0}$ extraction control was also found for GSP and TC compared with the 3P and NIO samplers, it cannot be excluded that the higher MNV recovery seen with GSP and TC may in part be due to an overall better extraction from these samples rather than due to a better collection efficiency. Our findings are, however, consistent with those of Kenny et al. (1999) that reported a higher sampling efficiency for GSP than for 3P when evaluated on aerosols generated from aluminum oxide grinding powder in a low air movement test environment. Likewise, the 3P sampler was found to give the lowest sampling efficiency of cultivable bacteria and fungi from indoor and outdoor environments compared with three other filter-based personal samplers (IOM, Button and a NIOSH 1-stage sampler) (Wang et al. 2015). According to our results, NIO also resulted in significantly lower MNV recovery than GSP. In contrast to the other personal sampler types tested in our study, NIO offers size fractioned collection of the viruses, which provides valuable information regarding the aerodynamic size of the airborne viruses. This information is useful in relation to determining where in the respiratory tract the viruses will be deposited and to estimate for how long time they will stay airborne. However, this feature also means that the collection tubes and filter must be extracted and analysed separately, which potentially could result in greater viral loss during processing and a lower total viral recovery. Thus, even though the NIO sampler has previously been used successfully for size-fractioned sampling of NoV, MNV, influenza virus and respiratory syncytial virus (Bonifait et al. 2015; Cao et al. 2011; Lindsley et al. 2010a; Lindsley et al. 2010b), our findings indicate that NIO may not be the best choice of sampler for recovery of airborne NoV.

This article is protected by copyright. All rights reserved. 
A difference in the size distribution of total aerosol particles and MNV in the chamber during aerosolisation was observed in our study. While the GMD of total particles measured in realtime with the ELPI+ was found to be $33.0 \pm 2.3$, the GMD of MNV was determined to be $126.8 \pm 2.9 \mathrm{~nm}$ after extraction of MNV genomes from the ELPI+ aluminium size disc. This difference in the aerodynamic size distribution found for total particles and MNV is likely a result of several factors. The ELPI+ may overestimate the number of particles with the smallest aerodynamic diameters as the collection efficiencies of the ELPI+ stages with the smallest cut diameters do not reach zero toward smaller particle sizes. This is a known side effect of secondary collection of particles by diffusion (Järvinen et al. 2014). In addition, presence of small non-viral particles originating from the liquid medium and smaller fragments of disintegrated MNV particles may contribute to the measured total particle distribution being left-skewed compared with that of MNV. Aggregation of several MNV virions into a larger particle could also cause the observed difference in size distribution.

Aggregation of airborne viruses is a well-known phenomenon (Verreault et al. 2008) and could certainly explain why a considerable fraction of MNV was found to have aerodynamic diameters > $0.4 \mu \mathrm{m}$ despite a very low total particle count being observed in this size range.

The GMD of the total aerosol particles measured with ELPI+ in our study is more than 10-fold lower than the GMD particle size of 0.89-1.08 $\mu \mathrm{m}$ measured with an Aerodynamic Particle Sizer (APS) during MNV aerosolisation by Bonifait et al. (2015). This incongruence can be explained by differences in aerosolisation conditions and equipment used for measuring the particle sizes. The APS used by Bonifer et al. (2015) is for instance designed to measure particles in the size range of 0.5 $-20 \mu \mathrm{m}$, while particles down to an aerodynamic size of $6 \mathrm{~nm}$ is measured with the ELPI+. As the diameter of a single MNV virion is approximately $30 \mathrm{~nm}$, measurement conducted with an APS will likely result in an overestimation of the aerodynamic size of MNV as also indicated from our findings with ELPI+.

This article is protected by copyright. All rights reserved. 
In conclusion, the sampling efficiency of aerosolised MNV was found to be significantly influenced by both sampler and filter type. The GSP sampler combined with a nylon filter was found to be the best method for personal filter-based sampling of airborne NoV as this combination gave the highest recovery of aerosolised MNV. This finding was supported by our recent study sampling airborne NoV at a hospital wastewater treatment plant, in which we demonstrated the applicability of the GSP sampler combined with the NY filter to capture and recover low concentrations of airborne NoV in environmental air (Uhrbrand et al. 2017). We believe that the air sampling method identified as being superior in this study can be a valuable tool for examining personal exposure to airborne NoV and studying the association between airborne exposure and infection.

\section{Acknowledgments}

This work was supported by grant DFF-1335-00183 from the Danish Council for Independent Research. We acknowledge Margit W. Frederiksen, the National Research Institute of the Working Environment, Denmark, and Resadije Idrizi, the Technical University of Denmark, Denmark, for excellent technical assistance. We also thank Karen Bo Frydendall, the National Research Institute of the Working Environment, Denmark, for proofreading the manuscript. Finally, we thank Dr William G. Lindsley, the Center of Disease Control, GA, USA, for kindly providing us with the 2-stage NIOSH sampler.

\section{Conflict of interest}

No conflict of interest declared.

This article is protected by copyright. All rights reserved. 


\section{References}

Bonifait, L., Charlebois, R., Vimont, A., Turgeon, N., Veillette, M., Longtin, Y., Jean, J. and Duchaine, C. (2015) Detection and quantification of airborne norovirus during outbreaks in healthcare facilities. Clin Infect Dis 61, 299-304.

Bosch, A., Sanchez, G., Abbaszadegan, M., Carducci, A., Guix, S., Le Guyader, F.S., Netshikweta, R., Pinto, R.M., Poel, W.H.M., Rutjes, S., Sano, D., Taylor, M.B., van Zyl, W.B., Rodríguez-Lázaro, D., Kovac, K. and Sellwood, J. (2011) Analytical methods for virus detection in water and food. Food Anal Methods 4, 4-12.

Brooks, J.P., Tanner, B.D., Josephson, K.L., Gerba, C.P., Haas, C.N. and Pepper, I.L. (2005) A national study on the residential impact of biological aerosols from the land application of biosolids. J Appl Microbiol 99, 310-322.

Burton, N.C., Grinshpun, S.A. and Reponen, T. (2007) Physical collection efficiency of filter materials for bacteria and viruses. Ann Occup Hyg 51, 143-151.

Cannon, J.L., Papafragkou, E., Geunwoo, W.P., Osborne, J., Jaykus, L.A. and Vinje, J. (2006) Surrogates for the study of norovirus stability and inactivation in the environment: a comparison of murine norovirus and feline calicivirus. J Food Protect 69, 2761-2765.

Cao, G., Noti, J.D., Blachere, F.M., Lindsley, W.G. and Beezhold, D.H. (2011) Development of an improved methodology to detect infectious airborne influenza virus using the NIOSH bioaerosol sampler. Journal of Environmental Monitoring 13, 3321-3328.

Carducci, A., Tozzi, E., Rubulotta, E., Casini, B., Cantiani, L., Rovini, E., Muscillo, M. and Pacini, R. (2000) Assessing airborne biological hazard from urban wastewater treatment. Water Res 34, 11731178.

Carducci, A., Verani, M., Lombardi, R., Casini, B. and Privitera, G. (2011) Environmental survey to assess viral contamination of air and surfaces in hospital settings. J Hosp Infect 77, 242-247.

Carducci, A., Donzelli, G., Cioni, L. and Verani, M. (2016) Quantitative microbial risk assessment in occupational settings applied to the airborne human adenovirus infection. Int J Environ Res Public Health 13.

Carducci, A., Federigi, I. and Verani, M. (2013) Virus occupational exposure in solid waste processing facilities. Ann Occup Hyg 57, 1115-1127.

Costafreda, M.I., Bosch, A. and Rosa, M. (2006) Development, evaluation, and standardization of a real-time TaqMan reverse transcription-PCR assay for quantification of hepatitis A virus in clinical and shellfish samples. Appl Environ Microbiol 72, 3846-3855.

D'Souza, D.H., Sair, A., Williams, K., Papafragkou, E., Jean, J., Moore, C. and Jaykus, L. (2006) Persistence of caliciviruses on enviromnental surfaces and their transfer to food. Int J Food Microbiol 108, 84-91.

Ettayebi, K., Crawford, S.E., Murakami, K., Broughman, J.R., Karandikar, U., Tenge, V.R., Neill, F.H., Blutt, S.E., Zeng, X.L., Qu, L., Kou, B., Opekun, A.R., Burrin, D., Graham, D.Y., Ramani, S., Atmar, R.L. and Estes, M.K. (2016) Replication of human noroviruses in stem cell-derived human enteroids.

Science 353, 1387-1393.

This article is protected by copyright. All rights reserved. 
Gendron, L., Verreault, D., Veillette, M., Moineau, S. and Duchaine, C. (2010) Evaluation of filters for the sampling and quantification of RNA phage aerosols. Aerosol Sci Technol 44, 893-901.

Gentry, J., Vinjé, J. and Lipp, E.K. (2009) A rapid and efficient method for quantitation of genogroups I and II norovirus from oysters and application in other complex environmental samples. J Virol Methods 156, 59-65.

Gilbert, Y., Duchaine, C. (2009) Bioaerosols in industrial environments: A review. Can J Civ Eng 36, 1873-1886.

Hogan, C.J., Kettleson, E.M., Lee, M.H., Ramaswami, B., Angenent, L.T. and Biswas, P. (2005) Sampling methodologies and dosage assessment techniques for submicrometre and ultrafine virus aerosol particles. J Appl Microbiol 99, 1422-1434.

Järvinen, A., Aitomaa, M., Rostedt, A., Keskinen, J., Yli-Ojanperä, J., 2014. Calibration of the new electrical low pressure impactor (ELPI+). Journal of Aerosol Science 69, 150-159.

Jones, M.K., Grau, K.R., Costantini, V., Kolawole, A.O., de Graaf, M., Freiden, P., Graves, C.L., Koopmans, M., Wallet, S.M., Tibbetts, S.A., Schultz-Cherry, S., Wobus, C.E., Vinje, J. and Karst, S.M. (2015) Human norovirus culture in B cells. Nat Protoc 10, 1939-1947.

Jothikumar, N., Cromeans, T.L., Hill, V.R., Lu, X., Sobsey, M.D. and Erdman, D.D. (2005) Quantitative real-time PCR assays for detection of human adenoviruses and identification of serotypes 40 and 41 . Appl Environ Microbiol 71, 3131-3136.

Kageyama, T., Kojima, S., Shinohara, M., Uchida, K., Fukushi, S., Hoshino, F.B., Takeda, N. and Katayama, K. (2003) Broadly reactive and highly sensitive assay for norwalk-like viruses based on real-time quantitative reverse transcription-PCR. J Clin Microbiol 41, 1548.

Kenny, L.C., Aitken, R.J., Baldwin, P.E.J., Beaumont, G.C. and Maynard, A.D. (1999) The sampling efficiency of personal inhalable aerosol samplers in low air movement environments. Journal of Aerosol Science 30, 627-638.

Koopmans, M., Duizer, E. (2004) Foodborne viruses: an emerging problem. Int J Food Microbiol 90, 23-41.

Le Guyader, F., Parnaudeau, S., Schaeffer, J., Bosch, A., Loisy, F., Pommepuy, M. and Atmar, R.L. (2009) Detection and quantification of noroviruses in shellfish. Appl Environ Microbiol 75, 618-624.

Lindsley, W.G., Blachere, F.M., Davis, K.A., Pearce, T.A., Fisher, M.A., Khakoo, R., Davis, S.M., Rogers, M.E., Thewlis, R.E., Posada, J.A., Redrow, J.B., Celik, I.B., Chen, B.T. and Beezhold, D.H. (2010a) Distribution of airborne influenza virus and respiratory syncytial virus in an urgent care medical clinic. Clinical Infectious Diseases 50, 693-698.

Lindsley, W.G., Blachere, F.M., Thewlis, R.E., Vishnu, A., Davis, K.A., Cao, G., Palmer, J.E., Clark, K.E., Fisher, M.A., Khakoo, R. and Beezhold, D.H. (2010b) Measurements of airborne influenza virus in aerosol particles from human coughs. Plos One 5.

Loisy, F., Atmar, R.L., Guillon, P., Le Cann, P., Pommepuy, M. and Le Guyader, F.S. (2005) Real-time RT-PCR for norovirus screening in shellfish. J Virol Methods 123, 1-7.

Makela, J.M., Koponen, I.K., Aalto, P. and Kulmala, M. (2000) One-year data of submicron size modes of tropospheric background aerosol in Southern Finland. Journal of Aerosol Science 31, 595-611.

This article is protected by copyright. All rights reserved. 
Marks, P.J., Vipond, I.B., Carlisle, D., Deakin, D., Fey, R.E. and Caul, E.O. (2000) Evidence for airborne transmission of norwalk-like virus (NLV) in a hotel restaurant. Epidemiol Infect 124, 481-487.

Marks, P.J., Vipond, I.B., Regan, F.M., Wedgwood, K., Fey, R.E. and Caul, E.O. (2003) A school outbreak of norwalk-like virus: Evidence for airborne transmission. Epidemiol Infect 131, 727-736.

Martin, L.R., Duke, G.M., Osorio, J.E., Hall, D.J. and Palmenberg, A.C. (1996) Mutational analysis of the mengovirus poly $(C)$ tract and surrounding heteropolymeric sequences. J Virol 70, 2027-2031.

Masclaux, F.G., Hotz, P., Gashi, D., Savova-Bianchi, D. and Oppliger, A. (2014) Assessment of airborne virus contamination in wastewater treatment plants. Environ Res 133, 260-265.

Neve, H., Laborius, A. and Heller, K.J. (2003) Testing of the applicability of battery-powered portable microbial air samplers for detection and enumeration of airborne Lactococcus lactis dairy bacteriophages. Kieler Milchw Forsch 55, 301-315.

Nørgaard, A.W., Jensen, K.A., Janfelt, C., Lauritsen, F.R., Clausen, P.A. and Wolkoff, P. (2009) Release of VOCs and particles during use of nanofilm spray products. Environ Sci Technol 43, 7824-7830.

Patel, M.M., Hall, A.J., Vinje, J. and Parashara, U.D. (2009) Noroviruses: A comprehensive review. Journal of Clinical Virology 44, 1-8.

Rames, E., Roiko, A., Stratton, H. and Macdonald, J. (2016) Technical aspects of using human adenovirus as a viral water quality indicator. Water Res 96, 308-326.

Rawsthorne, H., Phister, T.G. and Jaykus, L.A. (2009) Development of a fluorescent in situ method for visualization of enteric viruses. Appl Environ Microbiol 75, 7822-7827.

Reed, L.J., Muench, H. (1938) A simple method of estimating fifty per cent endpoints. Am J Epidemiol 27, 493-497.

Teunis, P.F.M., Moe, C.L., Liu, P., Miller, S.E., Lindesmith, L., Baric, R.S., Le Pendu, J. and Calderon, R.L. (2008) Norwalk virus: How infectious is it? J Med Virol 80, 1468-1476.

Tseng, C.C., Li, C.S. (2005) Collection efficiencies of aerosol samplers for virus-containing aerosols. Journal of Aerosol Science 36, 593-607.

Tseng, C.C., Chang, L.Y. and Li, C.S. (2010) Detection of airborne viruses in a pediatrics department measured using real-time qPCR coupled to an air-sampling filter method. J Environ Health 73, 22-28.

Uhrbrand, K., Schultz, A.C., Koivisto, A.J., Nielsen, U. and Madsen, A.M. (2017) Assessment of airborne bacteria and noroviruses in air emission from a new highly-advanced hospital wastewater treatment plant. Water Res 112, 110-119.

Uhrbrand, K., Schultz, A.C. and Madsen, A.M. (2011) Exposure to airborne noroviruses and other bioaerosol components at a wastewater treatment plant in Denmark. Food Environ Virol 3, 130-137.

Ulevicius, V., Willeke, K., Grinshpun, S.A., Donnelly, J., Lin, X.J. and Mainelis, G. (1997) Aerosolization of particles from a bubbling liquid: Characteristics and generator development. Aerosol Sci Technol 26, 175-190.

Verreault, D., Moineau, S. and Duchaine, C. (2008) Methods for sampling of airborne viruses. Microbiol Mol Biol Rev 72, 413-444.

This article is protected by copyright. All rights reserved. 
Wallis, C., Melnick, J.L., Rao, C.C. and Sox, T.E. (1985) Method for detecting viruses in aerosols. Appl Environ Microbiol 50, 1181-1186.

Wang, C.H., Chen, B.T., Han, B.C., Liu, A.C.-Y., Hung, P.C., Chen, C.Y. and Chao, H.J. (2015) Field evaluation of personal sampling methods for multiple bioaerosols. Plos One 10.

Wobus, C.E., Karst, S.M., Thackray, L.B., Chang, K.O., Sosnovtsev, S.V., Belliot, G., Krug, A., Mackenzie, J.M., Green, K.Y. and Virgin, H.W. (2004) Replication of norovirus in cell culture reveals a tropism for dendritic cells and macrophages. PLoS Biol 2, 2076-2084.

Zuo, Z., Kuehn, T.H., Verma, H., Kumar, S., Goyal, S.M., Appert, J., Raynor, P.C., Ge, S. and Pui, D.Y.H. (2013) Association of airborne virus infectivity and survivability with its carrier particle size. Aerosol Sci Technol 47, 373-382.

\section{Figure Legends}

Figure 1. Schematic illustration of the experimental design for the experiments conducted in the aerosol

chamber: (A) Box with Casella pumps connected to filter samplers via sampling ports in the chamber, (B)

bubble generator with MNV suspension, (C) neutraliser, (D) fan connected to HEPA filter used for pushing

air into the chamber during flushing procedure, (E) filter samplers, (F) ELPI+, (G) pump connected to HEPA filter used for drawing air out of chamber during flushing procedure, $(\mathrm{H})$ input for supplementary air via

HEPA filter.

Figure 2. Recovery of aerosolised MNV using various filter materials (A) and filter-based samplers (B). Samplers and filters were tested in duplicates on minimum two separate occasions. The concentrations of MNV recovered after sampling was normalised according to the total particle concentration in the chamber during sampling. MNV recovery from filters or samplers with same italic letter is not significantly different on a $95 \%$ significance level.

Figure 3. Aerosol size distribution of total particles (lines) and MNV (bars) in the chamber during sampling determined using ELPI+. Size distribution of background level of particles in the chamber measured prior to aerosolisation is shown in the dotted line. MNV was recovered from the ELPI+ plates using qRT-PCR. The geometric mean aerodynamic diameter (GMD) of total particles and MNV was $33.0 \pm 2.3$ and $126.8 \pm 2.9 \mathrm{~nm}$, respectively.

This article is protected by copyright. All rights reserved. 
Table 1. Mean recovery (\%) of murine norovirus (MNV), human norovirus (NoV) GIl.4 and adenovirus (AdV) spiked onto the various filter materials and ELPI+ discs on two separate occasions and detected by RT-qPCR in duplicates.

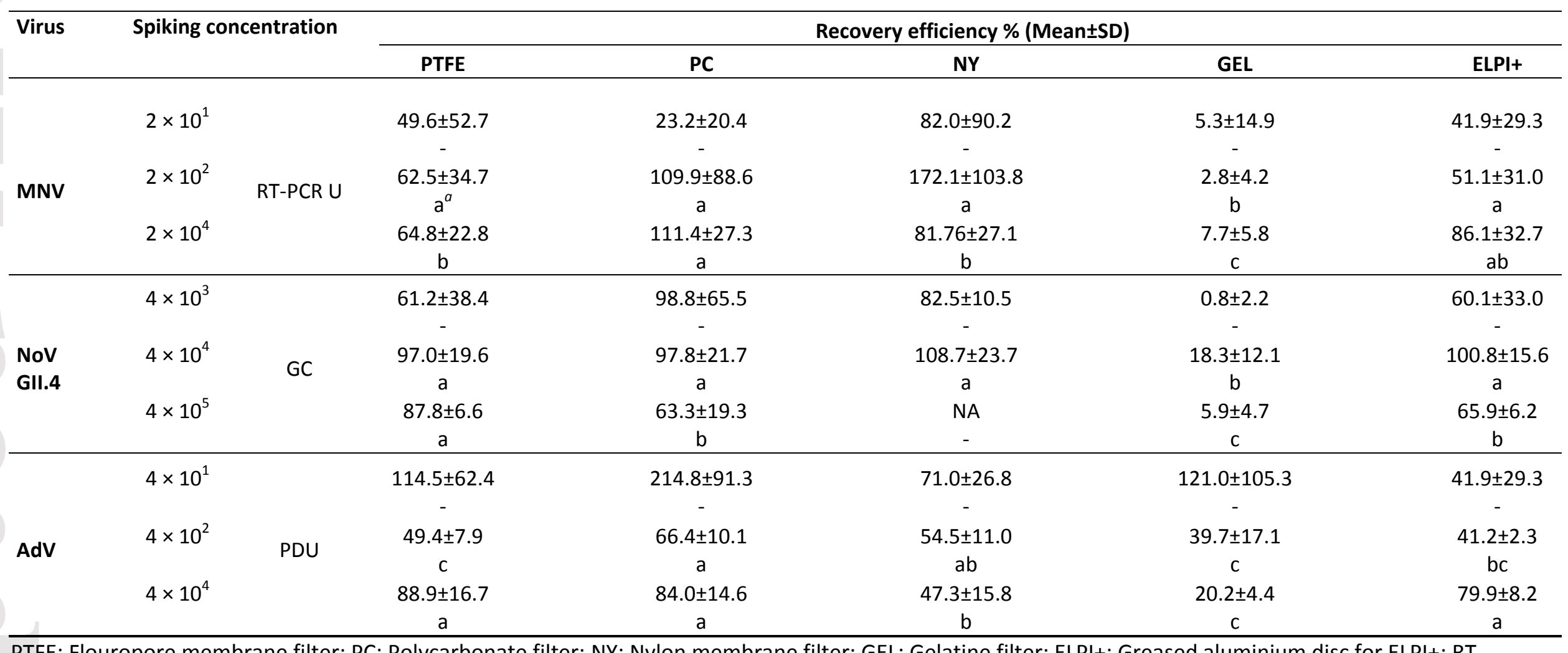

PTFE: Flouropore membrane filter; PC: Polycarbonate filter; NY: Nylon membrane filter; GEL: Gelatine filter; ELPI+: Greased aluminium disc for ELPI+; RT-

PCR U: Reverse transcriptase-PCR units; GC: Genomic copies; PDU: PCR-detectable units; NA: Not analysed

${ }^{a}$ Concentrations in the same row with same letter are not significantly different on a $95 \%$ significance level.

This article is protected by copyright. All rights reserved. 


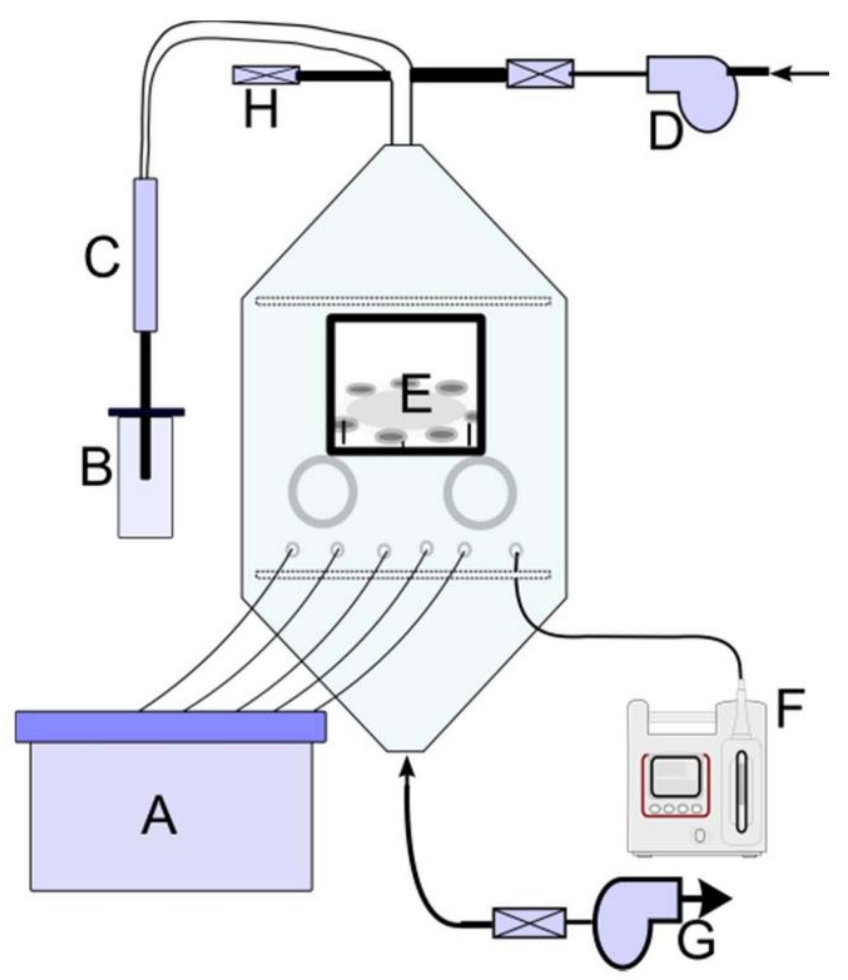

Figure 1. Schematic illustration of the experimental design for the experiments conducted in the aerosol chamber: (A) Box with Casella pumps connected to filter samplers via sampling ports in the chamber, (B) bubble generator with MNV suspension, (C) neutraliser, (D) fan connected to HEPA filter used for pushing air into the chamber during flushing procedure, (E) filter samplers, (F) ELPI+, (G) pump connected to HEPA filter used for drawing air out of chamber during flushing procedure, $(\mathrm{H})$ input for supplementary air via HEPA filter.

This article is protected by copyright. All rights reserved. 


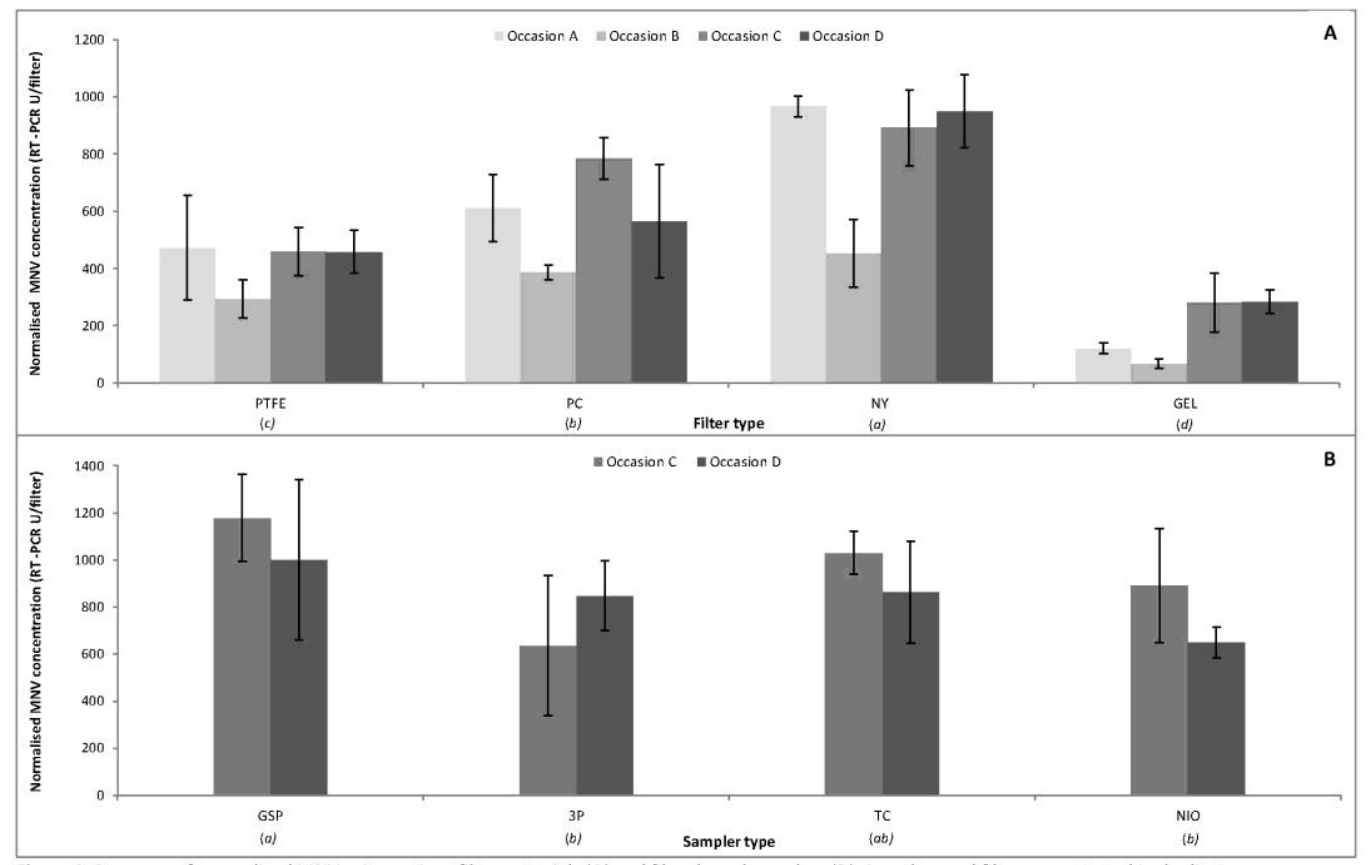

Figure 2. Recovery of aerosolised MNV using various filter materials (A) and filter-based samplers (B). Samplers and filters were tested in duplicates on minimum two separate occasions. The concentrations of MNV recovered after sampling was normalised according to the total particle concentration in the chamber during sampling. MNV recovery from filters or samplers with same italic letter is not significantly different on a $95 \%$ significance level.

This article is protected by copyright. All rights reserved. 


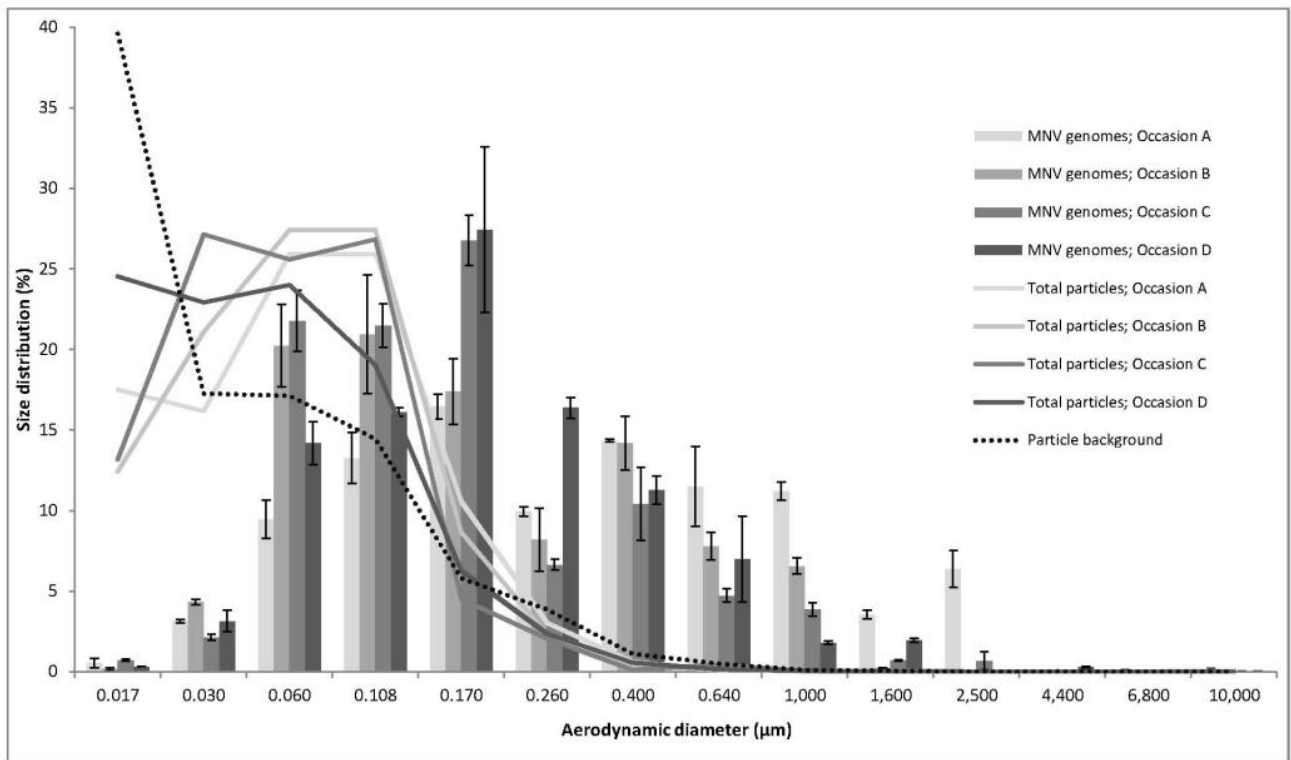

Figure 3. Aerosol size distribution of total particles (lines) and MNV (bars) in the chamber during sampling determined using ELPI+. Size distribution of background level of particles in the chamber measured prior to aerosolisation is shown in the dotted line. MNV was recovered from the ELPI+ plates using qRT-PCR. The geometric mean aerodynamic diameter (GMD) of total particles and MNV was $33.0 \pm 2.3$ and $126.8 \pm 2.9 \mathrm{~nm}$, respectively. 